\title{
Inter-comparison of the Impact of INSAT-3D Atmospheric Motion Vectors in 3DVAR and Hybrid Ensemble-3DVAR Data Assimilation Systems during Indian Summer Monsoon
}

Rekha Bharali Gogoi ( $\nabla$ rekha.bharali@nesac.gov.in )

North Eastern Space Applications Centre https://orcid.org/0000-0001-8770-6214

Govindan Kutty M

Indian Institute of Space Science and Technology https://orcid.org/0000-0002-7228-7288

Arup Borgohain

North Eastern Space Applications Centre

\section{Research Article}

Keywords: 3DVAR, ETKF, HYBRID, INSAT-3D, AMV, WRF, Indian summer monsoon

Posted Date: April 15th, 2021

DOI: https://doi.org/10.21203/rs.3.rs-418569/v1

License: (c) (i) This work is licensed under a Creative Commons Attribution 4.0 International License.

Read Full License 
Inter-comparison of the Impact of INSAT-3D Atmospheric Motion Vectors in 3DVAR and Hybrid Ensemble-3DVAR Data Assimilation Systems during Indian Summer Monsoon

\author{
Rekha Bharali \\ North Eastern Space Application Center, Umiam, India
}

Govindan Kutty*

Indian Institute of Space Science and Technology, Valiamala, India

Arup Boroghain

North Eastern Space Application Center, Umiam, India

*Corresponding Author:

Dr. Govindan Kutty M

Indian Institute of Space Science and Technology, Valiamala, India

govind@iist.ac.in 


\section{Declarations}

Funding: Not Applicable

Conflicts of interest/Competing interests: Not Applicable

\section{Availability of data and material:}

The NCEP global forecast system analyses and forecasts data that is utilized in this study are openly available in the repository https://rda.ucar.edu at https://doi.org/10.5065/D65Q4TSG. Data assimilation is performed using observations derived from NCEP ADP Global Upper Air and

Surface Weather Observations archived in the https://rda.ucar.edu at https://doi.org/10.5065/Z83F-N512 and INSAT-3D satellite derived atmospheric motion vectors from https://www.mosdac.gov.in.

\section{Code availability:}

The atmospheric model used in this study is Weather Research and Forecast (ARW-WRF) of version 3.8.1, which is openly available for download in https://www2.mmm.ucar.edu/wrf/users/download/get_sources.html. The data assimilation package comes from WRFDA system of 3.8.1 version archived in https://www2.mmm.ucar.edu/wrf/users/download/get_sources.html\#WRFDA.

\section{Authors' contributions:}

Rekha Bharali performed the experiments and wrote the manuscript. G Kutty analyzed the results. G Kutty and Arup Borgohain supervised the research work

Ethics approval: Not Applicable

Consent to participate: Not Applicable

Consent for publication: Not Applicable 


\begin{abstract}
The impact of observations may depend on various factors such as background error covariance in the data assimilation (DA) system. The present study compares the impact of INSAT-3D Atmospheric Motion Vector (AMV) observations in traditional three-dimensional variational (3DVAR) DA system and hybrid Ensemble Transform Kalman Filter (ETKF)-3DVAR DA system (HYBRID) available in Weather Research and Forecast (WRF) modeling system. The objective of the study is to understand how the impact of INSAT-3D AMV observations differ when assimilated using 3DVAR and HYBRID DA systems. The DA experiments are conducted over a $\sim 4$ week period of Indian Summer Monsoon Rainfall of July 2016. Four sets of experiments are performed with and without INSAT-3D AMV in both the DA systems. The domain-wide verification with respect to radiosonde observations reveals that forecasts in HYBRID experiments are more accurate than 3DVAR experiments, in general. Geographical distribution depicts the positive impacts of INSAT-3D AMV observations across the domain in both 3DVAR and HYBRID DA systems. The AMV observations show a larger relative impact in HYBRID than in 3DVAR. The relative improvement in HYBRID with AMV DA compared to 3DVAR is $77 \%$ and $71 \%$ for wind and tropical temperature. The skill scores for quantitative evaluation of precipitation forecast indicate a modest improvement in rainfall for HYBRID run and incorporating the AMV observation do not considerably enhance the skill of $24 \mathrm{~h}$ and $48 \mathrm{~h}$ rainfall forecast.
\end{abstract}

Key words: 3DVAR, ETKF, HYBRID, INSAT-3D, AMV, WRF, Indian summer monsoon 


\section{Introduction}

The importance of early warnings from the Numerical Weather Prediction (NWP) model has increased greatly in the last few decades as it plays an important role in mitigating the damages due to natural disasters like floods, thunderstorms, heavy rains, tropical cyclones, etc. NWP is an initial value problem, and its ability to represent the future state of the atmosphere depends primarily on the initial conditions of the atmosphere. The initial conditions for the limited area models are mostly derived from coarser-resolution global forecast models, which lack information about the region-specific local conditions. Data assimilation (DA) is a scientific method obtaining a very precise initial state of combining the background forecast and the observations (Daley 1991). Some of the widely used DA techniques such as three and four-dimensional variational method (3DVAR and 4DVAR) estimates the true state of the system based on the minimization of the cost function (e.g., Courtier et al. 1998; Wu et al. 2002; Bouttier and Kelly 2001). At the same time, the DA methods such as the ensemble Kalman filter (EnKF) estimate the optimal weights to obtain accurate initial conditions (Kalnay 2003). To preserve the accuracy of the state of the system, the distance between the background state and the observations are scaled by background error covariance (BEC) and observational error covariance. In the traditional variational approach, BEC is generated using climatological data and it is assumed to static and isotropic while the advanced DA methods such as EnKF utilizes the ensemble of the model forecast to compute BEC, which evolves with time. However, the implementation of EnKF in an operational forecast system is computationally intensive as its accuracy depends upon the ensemble size ( Houtekamer et al. 2005). In addition to that, the BEC is prone to sampling error due to limited ensemble number. Recently, a sophisticated DA system is developed by incorporating the flow-dependent BEC information provided by the ensemble members in the 3DVAR DA system, which is popularly 
known as the hybrid ensemble - 3DVAR DA system (hereafter HYBRID; Wang et al. 2007). The improved performance of HYBRID over 3DVAR is documented by many authors (e.g., Hamill and Snyder 2000; Wang et al. 2008; Prasad et al. 2016; Kutty and Wang 2015; Kutty et al. 2018). Atmospheric motion vectors (AMV) are satellite-derived wind observations, which are obtained by continuously tracking regions of clouds or water vapor using satellite images. AMV provides wind information with good areal coverage, particularly over the data-sparse oceanic region. Several studies have shown the benefit of assimilating AMVs on improving the weather forecasts over the tropics (eg.,Velden et al. 1992; Leslie et al. 1998; Soden et al. 2001; Rani and Gupta 2014; Mounika et al. 2018). A study by Kaur et al. (2015) during the Indian summer monsoon (ISM) reported a positive impact of Kalpana-1 AMV assimilation over the tropical region in the 3DVAR DA system. Deb et al. (2016) demonstrate the reduction of track forecast errors of the cyclonic storm NANAUK over the Arabian Sea when INSAT-3D AMV observations are assimilated. Kumar et al. (2017) has reported a positive impact of INSAT-3D AMV observations in the 3DVAR DA system during ISM.

The impact of observations may vary depending on many factors in the DA assimilation system such as data quality control, preprocessing, and specification of BEC. Previous studies have shown that in the presence of flow evolving BEC in HYBRID DA system the observations are effectively assimilated as compared to traditional 3DVAR DA systems, and hence it is expected that the impact of INSAT-3D AMV observations may vary in different DA systems. Recent studies have established the forecast improvements due to AMV observations in HYBRID DA system (e.g., Sawada et al. 2019; Zhang et al. 2018). The present study attempts to quantify the impact of assimilation of INSAT-3D AMV using the advanced HYBRID DA system using a $\sim 4$ weeks period of July 2016 using a limited area model. The specific objective of the study is to understand 
how different or similar the impact of INSAT-3D AMV observations by 3DVAR as compared to that assimilated by HYBRID DA system. This paper is organized as follows. Section 2 gives a detailed description of the DA systems, the model, and the experimental design. Section 3 describes the major results and Section 4 concludes the paper.

\section{Data and Methodology}

\subsection{Data assimilation systems:}

In this study, experiments are conducted using two DA systems namely 3DVAR and hybrid Ensemble Transform Kalman Filter (ETKF)-3DVAR available in Weather Research and Forecast Data Assimilation (WRFDA) system. The minimization cost function of HYBRID carries an additional term that incorporates ensemble covariance in the 3DVAR framework as shown below

$J\left(\boldsymbol{x}^{\prime}\right)=\beta_{1} \frac{1}{2}\left(\boldsymbol{x}_{\mathbf{1}}{ }^{\prime}\right)^{T} \boldsymbol{B}^{-1}\left(\boldsymbol{x}_{\mathbf{1}}{ }^{\prime}\right)+\beta_{2} \frac{1}{2} \boldsymbol{a}^{T} \boldsymbol{A}^{-\mathbf{1}} \boldsymbol{a}+\frac{1}{2}\left(y_{o}^{\prime}-\mathrm{H}\left(\boldsymbol{x}^{\prime}\right)\right)^{T} \boldsymbol{R}^{-1}\left(y_{o}^{\prime}-\mathrm{H}\left(\boldsymbol{x}^{\prime}\right)\right)$

where $\boldsymbol{x}^{\prime}$ is the analysis increment that has the contribution of both static and ensemble error covariances available in HYBRID, $\boldsymbol{B}$ is the static BEC matrix, $\boldsymbol{x}_{\mathbf{1}}{ }^{\prime}$ is the model space increment that has the contribution of static BEC of $3 \mathrm{DVAR}$ and $\beta_{1}$ is used to assign a weight to static BEC. Here, $\boldsymbol{a}$ consists of the spatially varying extended control variables (Lorenc 2003), and its variations are controlled by the localization matrix A. $\beta_{2} \frac{1}{2} \boldsymbol{a}^{T} \boldsymbol{A}^{-1} \boldsymbol{a}$ incorporates the flowdependent ensemble BEC information and $\beta_{2}$ is used to assign weight to the ensemble covariance (Wang et al. 2008). The present study assigns equal weight (50\%) to the static and flow-dependent ensemble BEC in the HYBRID cost function. The static BEC matrix used in this study is generated using the National Meteorological Center (NMC; Parrish and Derber 1992) method from one month of WRF generated model forecast using CV5 option. In equation (1), $y_{o}^{\prime}=\left(y_{o}-H\left(x_{b}\right)\right)$ 
is the innovation vector where $y_{o}$ is the observation, $x_{b}$ is the background forecast and $H$ is the nonlinear observation operator. Here, $\mathrm{H}$ is the linearized observation operator and $\mathbf{R}$ is the observation error covariance matrix.

The forecast ensemble perturbations are updated by ETKF using the following transformation matrix T:

$$
\mathbf{T}=\mathbf{C}(\Gamma+\mathbf{I})^{-\frac{1}{2}} \mathbf{C}^{\mathrm{T}}
$$

where $\Gamma$ represnts the eigen values and $\mathbf{C}$ represents the eigenvectors obtained by the singular value decomposition of $\left(\mathbf{H X}^{\mathbf{b}}\right)^{\mathrm{T}} \mathbf{R}^{-\mathbf{1}} \mathbf{H} \mathbf{X}^{\mathbf{b}}$. The under-sampling problem associated with ETKF due to small ensemble size is dealt with adding inflation factors $\Pi$ and $\rho$ that increases the analysis error variance (Wang et al. 2008):

$$
\mathbf{X}^{\mathrm{a}}=\mathbf{X}^{\mathbf{b}} \mathbf{C}(\rho \Gamma+\mathbf{I})^{-\frac{1}{2}} \mathbf{C}^{\mathrm{T}} \Pi
$$

Since covariance localization has not been applied to the ETKF formulation, large inflation factors are used to improve the systematic underestimation in the error variance. The initial perturbations for ensembles are obtained as random draws from the static BEC of 3DVAR. Further details on the configurations of the DA systems can be found in Gogoi et al. (2020)

\subsection{Model Description and Configurations}

The model simulations are performed using the Advanced Weather Research and Forecasting (ARW-WRF) model of version 3.8.1 (Skamarock et al. 2008). The model is fully compressible and non-hydrostatic that utilizes sophisticated parameterization schemes to represent unresolved atmospheric processes. The configuration of the model domain and the various schemes used in this study are shown in Table 1 . Figure 1 represents the simulation domain used in this study that 
covers the monsoon prevailing region in and around the Indian subcontinent. The initial and boundary conditions for WRF simulations are obtained from the National Center for Environmental Prediction (NCEP) Global Forecast System (GFS) data.

\subsection{Data used for assimilation}

\subsubsection{INSAT-3D AMV and Global Telecommunication System data}

INSAT-3D is an Indian geostationary meteorological satellite with the imager and the sounder onboard. The imager has one visible channel and five infrared (IR) channels namely short-wave IR (SWIR), mid-wave IR (MIR), water vapor (WV), and two split thermal IR (TIR-1, TIR-2) channels. The channels have different ground resolutions. Both visible and SWIR channels are at $1 \mathrm{~km}$ resolution, the MIR and TIRs channels are at $4 \mathrm{~km}$ ground resolution and the WV channel is comparatively at a coarser resolution of $8 \mathrm{~km}$. INSAT-3D sounder has $18 \mathrm{IR}$ and one visible channel. Out of the 18 IR channels, six bands are in the SWIR, five are in the MIR, seven channels are in the longwave infrared (LWIR). The ground resolution of all sounder channels is $10 \mathrm{~km}$. Three consecutive INSAT-3D images of 30-minute intervals are used to determine the AMVs, which consists of the following steps 1) Image registration, thresholding, filtering, 2) Features/tracer selection and tracking, 3) Quality control and 4) Height assignment (Sankhala et al. 2020). This study uses AMVs retrieved from low-level MIR and visible channels extended from $600 \mathrm{hPa}$ to $950 \mathrm{hPa}$, and upper-level WV channel data ranges from 100 to $500 \mathrm{hPa}$. A Recent study shows that INSAT-3D AMV is found to be useful in understanding the monsoon intraseasonal variability of ISM (Sankhala et al. 2019). AMV data for this study is obtained from 
https://www.mosdac.gov.in/. Conventional in situ observations and satellite-derived wind observations available from the Global Telecommunication System (GTS) are assimilated.

\subsection{Experimental design and validation}

Observation System Experiment (OSE) is conducted to understand the impact of INSAT-3D AMV in 3DVAR and HYBRID DA systems and the details of experiments are provided in Table 2. Four experiments are conducted and the DA system is continuously cycled for $\sim 4$ week period starting from 0000 UTC 1 July 2016 to 0000 UTC 30 July 2016 at every 12-hour interval, and $48 \mathrm{~h}$ free forecast is commenced from each 0000 and 12 UTC DA analysis during the month of July. To avoid spin-up issues, the ensembles are initialized $24 \mathrm{~h}$ prior to the first analysis time i.e. 0000 UTC 30 June 2016, by adding 50 random perturbation from WRF 3DVAR. The 50 member ensemble system is then updated using ETKF after $24 \mathrm{~h}$ of model integration. The ensemble mean is used to initialize both 3DVAR and HYBRID experiments at 0000 UTC 1 July 2016. The observation errors are taken from NCEP statistics, and the error statistics for INSAT3D AMV are adapted from Kumar et al. (2017).

IMD gridded rainfall data at $\sim 25 \mathrm{~km}$ resolution (Pai et al. 2014) is used to validate the rainfall forecast. Further, the European Center for Medium Range Weather Forecasting Reanalysis (ERA) interim and Advanced Scatterometer (ASCAT) data are used for verification of atmospheric field variables. Prior to validation, the model simulations from all the experiments are brought to the same grid resolution as ASCAT and ERA interim data using bilinear interpolation. Verification metrics used in this study involves root mean square error (RMSE), mean error (ME) or Bias and improvement parameter $(\eta)$. The improvement parameter is calculated as shown below (4). 
Improvement parameter $\eta=\left[1-\frac{R M S E_{E X P}}{R M S E_{3 D V A R}}\right] \times 100$

Positive $\eta(\%)$ values depict improvement in 3DVAR_AMV, HYBRID, HYBRID_AMV in comparison to 3DVAR. The rainfall forecast is further validated using Bias Score (BS) and Equitable Threat Score (ETS) (Hamill and Juras 2006).

\section{Results}

\subsection{Analysis and Forecast Profile Verification}

Figure 2 indicates the profiles of root mean square fit of analysis to the observation for zonal and meridional winds, temperature, and water vapor mixing ratio validated against radiosonde observations. The values are obtained by averaging over 60 DA cycles and over the domain, which is shown in Figure 1. It can be seen that HYBRID analysis without AMV observations fit more closely to the observations for zonal and meridional winds, while 3DVAR experiments show slightly better fit to observations for temperature and water vapor mixing ratio in almost all the levels. The analysis from 3DVAR and 3DVAR_AMV experiments depicts a similar fit to the observation for all the variables. It is to be noted that the radiosonde observations used for validating the analysis are also assimilated to the analysis. Hence the results may not represent the error in the analysis. However, it is indicative of how close the analysis is to the observations. In general, the fit of analysis to observations are closely tied to the configurations of 3DVAR and HYBRID algorithms and its BEC settings. Previous studies such as Wang (2008) show that for smaller background error variances or larger correlation length-scales the analysis may not fit well with the observations. In addition to that, Zhang et al. (2011) has shown that a closer fit to observations does not necessarily lead to a better forecast. To further assess the impact of observations on the model variables, the vertical profile of analysis increment at the radiosonde 
location is evaluated (Fig. 3). The varying effect of two different DA techniques is quite visible in the zonal wind analysis increment. Both HYBRID experiments show strong upper-level zonal wind increment compared to 3DVAR experiments. No significant impact of AMV is observed in the HYBRID experiments. However, for meridional wind, AMV data's influence is seen in 3DVAR from $400 \mathrm{hPa}$ to $800 \mathrm{hPa}$. The temperature field result shows a negative temperature increment for all the experiments from $1000 \mathrm{hPa}$ to $500 \mathrm{hPa}$. However, the magnitude of increment is higher in both the HYBRID experiments. In the upper level above $500 \mathrm{hPa}$, HYBRID_AMV shows a larger positive increment compared to other experiments.

The root mean square error (RMSE) is computed with respect to radiosonde observations for 24 $\mathrm{h}$ forecasts initialized from the analysis at 0000 UTC of the month of July 2016, which is shown in Figure 4. The results indicate that both the HYBRID experiments are more accurate than the 3DVAR experiments. The wind forecast shows improvement mostly near the upper troposphere, while the improvement in the temperature forecast in HYBRID experiments are substantially larger as compared to 3DVAR experiments. For wind forecasts, the impact of AMV is more

evident in 3DVAR than HYBRID. Having said these, the impact of AMV observations by the domain averaged vertical profiles of field variables are not evident from Figure 4 . The forecast validation is done with respect to radiosonde observation, which is absent over oceans. Therefore, the actual impact of AMV observations may not be reflected when verified over limited radiosonde profiles.

\subsection{Spatial Forecast verification}

To further assess the impact of observations as well as DA system on the model forecast, the significant zone of forecast difference between 3DVAR and the rest of the experiments are 
evaluated for model variables namely wind at $850 \mathrm{hPa}$ level, tropospheric temperature (TT) averaged over $200 \mathrm{hPa}$ to $700 \mathrm{hPa}$ level and relative humidity (RH) at $850 \mathrm{hPa}$ level (Figure not shown). The spatial representation of forecast difference shows an overall more significant difference zone in HYBRID experiments than 3DVAR_AMV simulations. More impact on TT field is observed over Bay of Bengal (BoB) and southern oceanic region.

Figure 5a,e,i depicts the monthly averaged wind at $850 \mathrm{hPa}$ level, TT, and RH at $850 \mathrm{hPa}$ level from ERA-interim reanalysis data respectively and Figure 5b-d,f-h,j-1 illustrates the spatial distribution of improvement parameter $(\eta)$ for the respective variables for July 2016 . The positive (negative) $\eta$ value represents percentage improvement (degradation) in the model forecast compared to the 3DVAR experiment. Both the HYBRID experiments depict higher positive $\eta$ values, which is indicative of improvements due to incorporating ensemble covariance in the 3DVAR framework for wind and TT variables. Further, the experiments that assimilate INSAT3D AMV observations show substantial relative forecast improvements in both 3DVAR and HYBRID DA systems, spatially. The largest positive impact is seen in HYBRID_AMV experiments with $77 \%$ positive $\eta$ values for wind. A dipole like pattern with positive and negative impact is observed over the western Arabian Sea (AS) due to the presence of Low Level Jet (LLJ) in Figure 5 b-d. LLJ is also known as Findlater Jet (Findlater 1978) is an important lower level circulation feature of the Indian summer monsoon, which carries extensive moisture from the Indian Ocean producing rainfall over the Indian subcontinent. Therefore, the improvement in the forecast of LLJ is expected to improve the rainfall over Indian landmass.

Apart from wind, a substantial improvement of $70 \%$ positive $\eta$ values for TT variable is observed in HYBRID_AMV experiment (Figure 5h). The improvement percentage for RH is not very 
significant compared to wind and TT. However, marginal improvement due to AMV DA is observed both in 3DVAR and HYBRID.

Figure 6 shows the time series of area averaged RMSE of zonal and meridional wind over the AS, respectively, for both $24 \mathrm{~h}$ and $48 \mathrm{~h}$ forecasts. The verification is confined to AS to understand the impact of experiments on LLJ. It is evident from Figure 6a and 6c that the assimilation of INSAT-3D AMV observations has significantly reduced the $24 \mathrm{~h}$ and $48 \mathrm{~h}$ forecasts errors for zonal winds in HYBRID_AMV experiment as compared to other experiments and the impact of assimilation increases with increase in time that is indicative of the cumulative impact of assimilation. Though the HYBRID experiment does not significantly improve $24 \mathrm{~h}$ forecasts, the reduction in forecast errors is clearly evident in $48 \mathrm{~h}$ forecast. In 3DVAR DA system, the positive impact of INSAT3D-AMV observations is evident during the later DA cycling hours.

To explore further on the impact of observations closer to the surface, 10 -m surface wind forecast is evaluated with respect to ASCAT wind observations over the AS region. Figure 7 shows the time series plot of monthly averaged RMSE of $24 \mathrm{~h}$ and $48 \mathrm{~h}$ near surface zonal and meridional wind forecast over the AS. Similar to the results obtained in ERA-interim validation, the assimilation of AMV observations has produced substantial improvements in the wind forecasts in both 3DVAR and HYBRID DA systems, in general. However, the 3DVAR_AMV experiment depicts higher reduction in forecast errors as compared to the other experiments for zonal wind. The improvement in meridional wind component is more pronounced in HYBRID_AMV run as compared to other experiments for both $24 \mathrm{~h}$ and $48 \mathrm{~h}$ forecasts.

\subsection{Rainfall forecast verification}


Figure 8 shows the mean error (Bias) of the model simulated $24 \mathrm{~h}$ rainfall forecast with respect to IMD gridded rainfall. The HYBRID experiments show lower Bias in precipitation as compared to 3DVAR run. It can be seen that the wet bias in the Central India (CI) and dry bias to the south of $\mathrm{CI}$ has shown considerable reduction in HYBRID experiments. The AMV experiments do not depict any significant change in Bias when compared to its corresponding control DA experiments. Further, the difference of 3DVAR forecasted rainfall from 3DVAR_AMV experiments shows no significant difference zone. The difference of 3DVAR from HYBRID, HYBRID_AMV experiments shows a considerable difference zone over the same region where HYBID has improved wet bias and dry bias compared to 3DVAR. HYBRID_AMV also shows significant difference over southern CI and north eastern region of India for both $24 \mathrm{~h}$ and $48 \mathrm{~h}$ forecast (Figure not shown).

To quantitatively evaluate the precipitation forecasts, skill scores such as ETS and Bias score are calculated for various experiments. It is to be noted that the skill scores are calculated in two phases of experiments: Phase-1 (2 - 16 July, 2016) and Phase-2 (17 - 31 July 2016), which is represented in Figure 9. The skill of $24 \mathrm{~h}$ precipitation forecast for HYBRID experiments are found to be higher than 3DVAR experiments in Phase-2 towards higher rainfall thresholds, which is evident from ETS values (Figure 9c). The HYBRID_AMV experiment shows improved skills for precipitation forecast for higher rainfall thresholds as compared to 3DVAR_AMV experiment in Phase-2. Bias score indicates that all the experiments in Phase-1 and Phase-2 shows overestimation of rainfall and the results are more pronounced in 3DVAR experiments in Phase2. Similarly, $48 \mathrm{~h}$ rainfall forecast results do not show substantial improvement in both the HYBRID experiment in Phase-I (Figure 10a). However, in Phase -2, the skill scores indicate modest improvements in rainfall forecast in moderate-high rainfall threshold for HYBRID 
experiment as compared to that of 3DVAR (Figure 10c). Furthermore, the assimilation of AMV observations does not significantly improve the precipitation forecast in both 3DVAR and HYBRID experiments.

\section{Conclusion}

In this study, the impact of assimilation of INSAT-3D AMV in the two DA systems for shortrange forecast during the Indian summer monsoon season is evaluated. The DA systems used in this study include 3DVAR and HYBRID available in the WRF modeling system. The DA cycling experiments are performed for the $\sim 4$ week period of July 2016 and a $48 \mathrm{~h}$ model forecast is generated from each analysis.

The results indicate that 3DVAR analysis fits more closely with the observations than HYBRID analysis. The domain-wide verification with respect to radiosonde observations reveals that forecasts in HYBRID experiments are more accurate than the 3DVAR experiments, in general. The wind forecasts show more improvements near the upper troposphere for HYBRID run, with the nominal impact of INSAT-3D AMV observations. In comparison with the forecasts from HYBRID analysis, the impact of INSAT-3D AMV observations is more pronounced in 3DVAR DA system, for wind forecasts over land. Geographical distribution depicts the positive impacts of INSAT-3D AMV observations with respect to ERA-Interim analysis across the whole domain in both 3DVAR and HYBRID DA systems. The AMV observations show a larger relative impact in HYBRID than in 3DVAR and the relative improvement in comparison to 3DVAR is $77 \%$ for

wind and $71 \%$ for tropospheric temperature. Time evolution of forecast errors with respect to ERA-Interim analysis in the zonal wind over the Arabian Sea indicates a larger growth rate in 3DVAR experiment in comparison to HYBRID experiment while the assimilation of AMV 
observations considerably reduces forecast errors in both DA systems. The HYBRID_AMV experiments show improvement in the meridional component of near surface winds when validated against ASCAT observations. The HYBRID run reduces the Bias in precipitation forecast, especially when AMV observations are incorporated. The skill scores for quantitative evaluation of precipitation forecast indicates a modest improvement in rainfall for HYBRID run, and incorporating the AMV observation do not considerably enhance the skill of $24 \mathrm{~h}$ and $48 \mathrm{~h}$ rainfall forecast.

The present study attempts to quantify the impact of INSAT-3D AMV observation in the 3DVAR and the hybrid ETKF-3DVAR DA system. The HYBRID DA system incorporates flowdependent ensemble BEC that generates optimal analysis through increments that are consistent with the background flow, and respond adaptively to the change in the observing system. Therefore, it is expected that the impact of the observing system may vary depending on the DA system used. As a matter of fact, the results from the study indicate that the impact of INSAT3D AMV observations varies in 3DVAR and HYBRID DA systems. Further, the impact of the new observing system shows more value to the advanced DA systems such as HYBRID than the traditional 3DVAR approach. However, the ensemble system needs to be properly configured for the DA system to perform optimally. Further, the study has not assimilated satellite radiance observation. The impact of INSAT-3D AMV may differ considerably in both the DA systems when satellite radiance is incorporated. Future studies in this direction are warranted.

\section{Acknowledgement:}

The authors thankfully acknowledge the Indian Institute of Tropical Meteorology for providing us High Performance Computing resources. 


\section{Data Availability:}

The NCEP global forecast system analyses and forecasts data that is utilized in this study are openly available in the repository https://rda.ucar.edu at https://doi.org/10.5065/D65Q4TSG. Data assimilation is performed using observations derived from NCEP ADP Global Upper Air and

Surface Weather Observations archived in the https://rda.ucar.edu at https://doi.org/10.5065/Z83F-N512 and INSAT-3D satellite derived atmospheric motion vectors from https://www.mosdac.gov.in.

\section{References:}

Bouttier, F., and G. Kelly, 2001: Observing - system experiments in the ECMWF 4D - Var data assimilation system. Q J R Meteorol Soc, 127, 1469-1488.

Courtier, P., and Coauthors, 1998: The ECMWF implementation of three - dimensional variational assimilation (3D - Var). I: Formulation. Q J R Meteorol Soc, 124, 1783-1807.

Daley, 1991: Atmospheric Data Analysis. Vol. 2, Cambridge Univ.

Deb, S., C. Kishtawal, P. Kumar, A. K. Kumar, P. Pal, N. Kaushik, and G. Sangar, 2016: Atmospheric Motion Vectors from INSAT-3D: Initial quality assessment and its impact on track forecast of cyclonic storm NANAUK. Atmos Res, 169, 1-16.

Findlater, J., 1978: Observational aspects of the low-level cross-equatorial jet stream of the western Indian Ocean. Monsoon Dynamics, Springer, 1251-1262.

Gogoi, R. B., G. Kutty, V. Rakesh, and A. Borogain, 2020: Comparison of the Performance of Hybrid ETKF3DVAR and 3DVAR Data Assimilation Systems on Short-Range Forecasts during Indian Summer Monsoon Season in a Limited-Area Model. Pure Appl Geophys, 1-20.

Hamill, T. M., and C. Snyder, 2000: A hybrid ensemble Kalman filter-3D variational analysis scheme. Mon Weather Rev 128, 2905-2919.

Hamill, T. M., and J. Juras, 2006: Measuring forecast skill: Is it real skill or is it the varying climatology? Q J $R$ Meteorol Soc, 132, 2905-2923.

Houtekamer, P. L., H. L. Mitchell, G. Pellerin, M. Buehner, M. Charron, L. Spacek, and B. Hansen, 2005: Atmospheric data assimilation with an ensemble Kalman filter: Results with real observations. Mon Weather Rev, 133, 604-620.

Kalnay, E., 2003: Atmospheric modeling, data assimilation and predictability. Cambridge university press. Kaur, I., P. Kumar, S. Deb, C. Kishtawal, P. Pal, and R. Kumar, 2015: Impact of Kalpana-1 retrieved atmospheric motion vectors on mesoscale model forecast during summer monsoon 2011. Theor Appl Climatol, 120, 587-599.

Kumar, P., S. K. Deb, C. Kishtawal, P. J. T. Pal, and a. climatology, 2017: Impact of assimilation of INSAT-3D retrieved atmospheric motion vectors on short-range forecast of summer monsoon 2014 over the south Asian region, 128, 575-586. 
Kutty, G., and X. Wang, 2015: A Comparison of the Impacts of Radiosonde and AMSU Radiance Observations in GSI Based 3DEnsVar and 3DVar Data Assimilation Systems for NCEP GFS. Adv Meteorol, 2015.

Kutty, G., R. Muraleedharan, and A. P. Kesarkar, 2018: Impact of Representing Model Error in a Hybrid Ensemble-Variational Data Assimilation System for Track Forecast of Tropical Cyclones over the Bay of Bengal. Pure Appl Geophys, 175, 1155-1167.

Leslie, L., J. LeMarshall, R. Morison, C. Spinoso, R. Purser, N. Pescod, and R. Seecamp, 1998: Improved hurricane track forecasting from the continuous assimilation of high quality satellite wind data. Mon Weather Rev, 126, 1248-1258.

Lorenc, A., 2003: The potential of the ensemble Kalman filter for NWP-a comparison with 4D - Var. $Q J R$ Meteorol Soc, 129, 3183-3203.

Mounika, K., G. Kutty, and S. S. R. Gorthi, 2018: Consistent Robust and Recursive Estimation of Atmospheric Motion Vectors From Satellite Images. IEEE Geosci Remote S, 57, 1538-1544.

Pai, D., L. Sridhar, M. Rajeevan, O. Sreejith, N. Satbhai, and B. Mukhopadhyay, 2014: Development of a new high spatial resolution $(0.25 \times 0.25)$ long period $(1901-2010)$ daily gridded rainfall data set over India and its comparison with existing data sets over the region. Mausam, 65, 1-18.

Parrish, D. F., and J. C. Derber, 1992: The National Meteorological Center's spectral statisticalinterpolation analysis system. Mon Weather Rev, 120, 1747-1763.

Prasad, V., C. Johny, and J. S. Sodhi, 2016: Impact of 3D Var GSI-ENKF hybrid data assimilation system. J Earth Syst Sci, 125, 1509-1521.

Rani, S. I., and D. Gupta, 2014: An inter - comparison of K alpana - 1 and M eteosat - 7 atmospheric motion vectors against radiosonde winds and NWP forecasts during monsoon 2011. Meteorological Applications, 21, 820-830.

Sankhala, D. K., S. K. Deb, and V. Sathiyamoorthy, 2019: INSAT-3D low-level atmospheric motion vectors: Capability to capture Indian summer monsoon intra-seasonal variability. J Earth Syst Sci, 128, 31.

Sankhala, D. K., S. K. Deb, S. K. Sharma, and S. Lal, 2020: Inter-comparison of INSAT-3D atmospheric motion vectors height with cloud-base height from a Ceilometer. Int J Remote Sens 41, 2946-2961.

Sawada, M., Z. Ma, A. Mehra, V. Tallapragada, R. Oyama, and K. Shimoji, 2019: Impacts of Assimilating High-Resolution Atmospheric Motion Vectors Derived from Himawari-8 on Tropical Cyclone Forecast in HWRF. Mon Weather Rev, 147, 3721-3740.

Skamarock, W. C., and Coauthors, 2008: G.: A description of the Advanced Research WRF version 3. NCAR Tech. Note NCAR/TN-475+STR, Citeseer.

Soden, B. J., C. S. Velden, and R. E. Tuleya, 2001: The impact of satellite winds on experimental GFDL hurricane model forecasts. Mon Weather Rev, 129, 835-852.

Velden, C. S., C. M. Hayden, W. Paul Menzel, J. L. Franklin, and J. S. Lynch, 1992: The impact of satellitederived winds on numerical hurricane track forecasting. Weather Forecast, 7, 107-118.

Wang, X., C. Snyder, and T. M. Hamill, 2007: On the theoretical equivalence of differently proposed ensemble-3DVAR hybrid analysis schemes. Mon Weather Rev, 135, 222-227.

Wang, X., D. M. Barker, C. Snyder, and T. M. Hamill, 2008: A hybrid ETKF-3DVAR data assimilation scheme for the WRF model. Part I: Observing system simulation experiment. Mon Weather Rev, 136, 5116-5131.

Wu, W.-S., R. J. Purser, and D. F. Parrish, 2002: Three-dimensional variational analysis with spatially inhomogeneous covariances. Mon Weather Rev, 130, 2905-2916.

Zhang, S., Z. Pu, and C. Velden, 2018: Impact of enhanced atmospheric motion vectors on HWRF hurricane analyses and forecasts with different data assimilation configurations. Mon Weather Rev, 146, 1549-1569. 
Figures

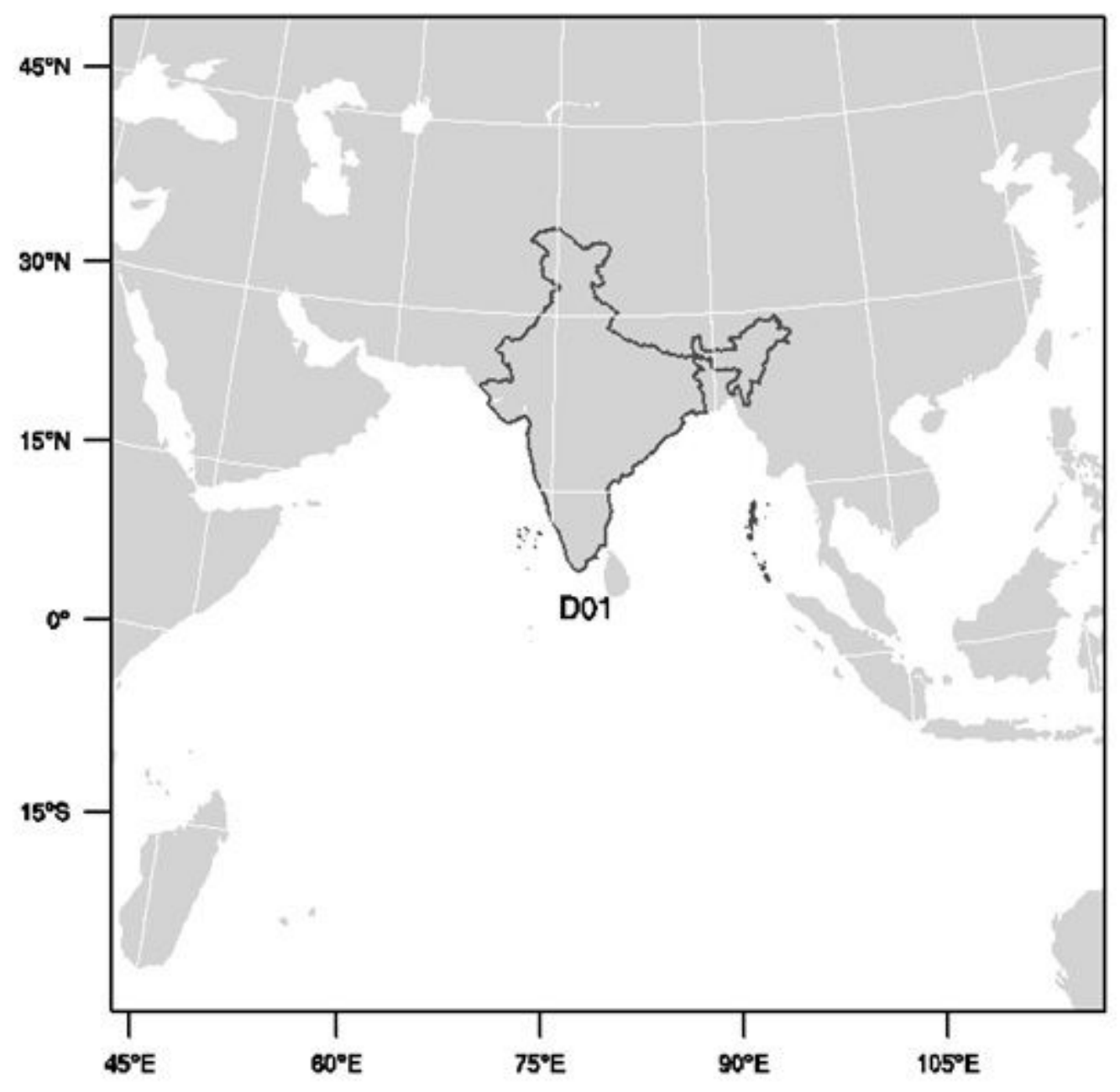

Figure 1

Model configuration deployed in this study. 

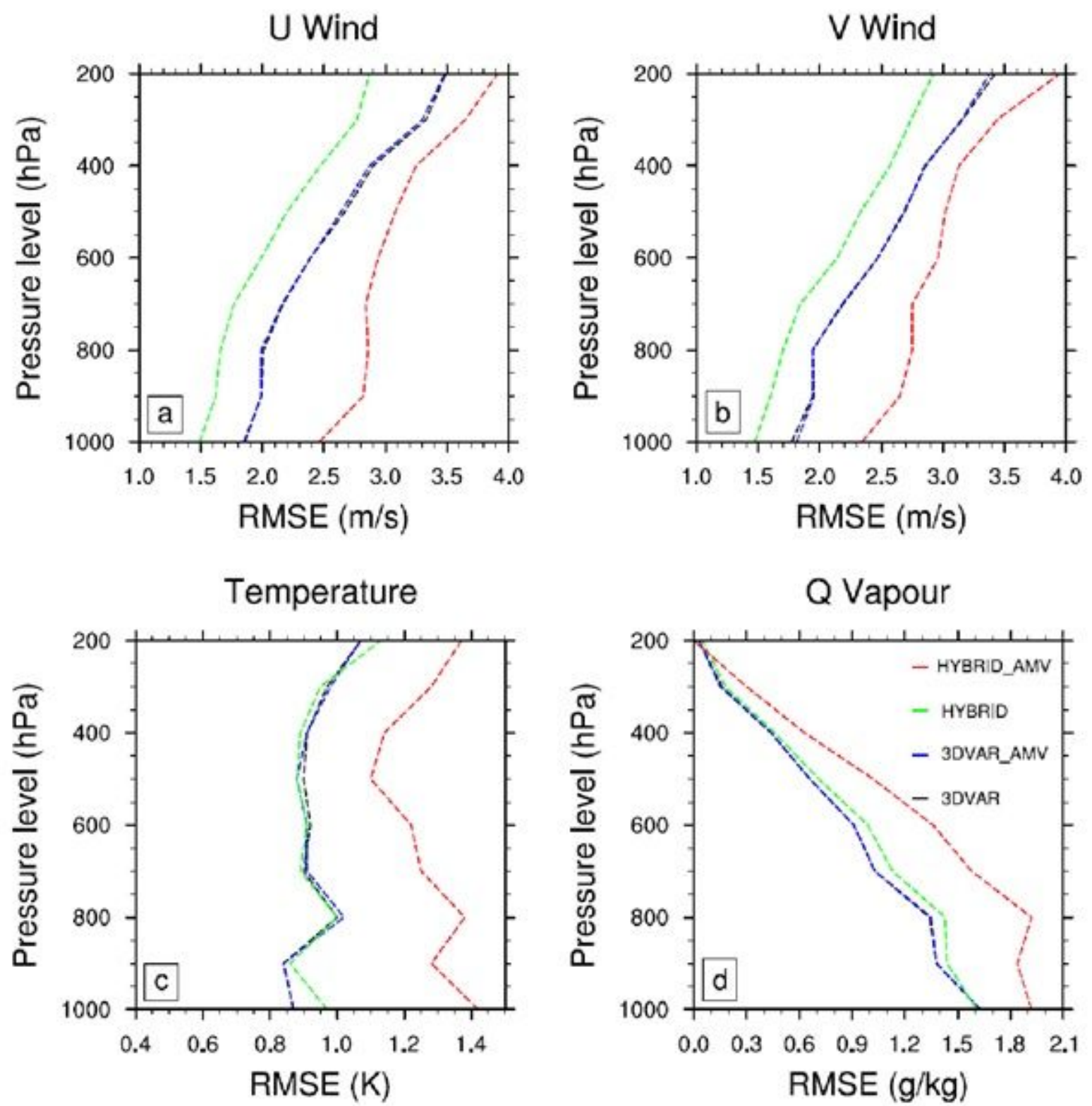

Figure 2

Vertical profiles of root mean square fit of analysis to radiosonde observations for different prognostic variables; analyzed by 3DVAR (black line),3DVAR_AMV (blue line), HYBRID (green line) and HYBRID_AMV(red line) experiments. 

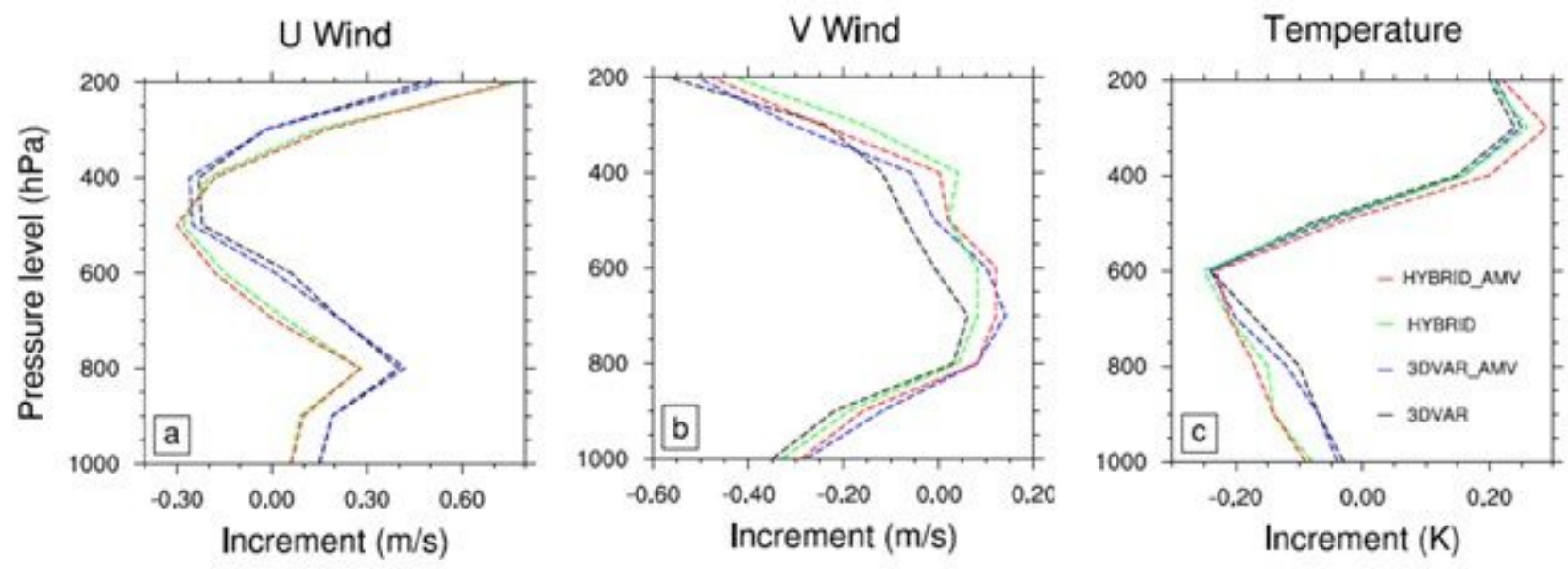

\section{Figure 3}

Vertical profiles of analysis increment (Analysis-Background) for three different prognostic variables; analyzed by 3DVAR (black line), 3DVAR_AMV (blue line), HYBRID (green line) and HYBRID_AMV (red line) experiments. 

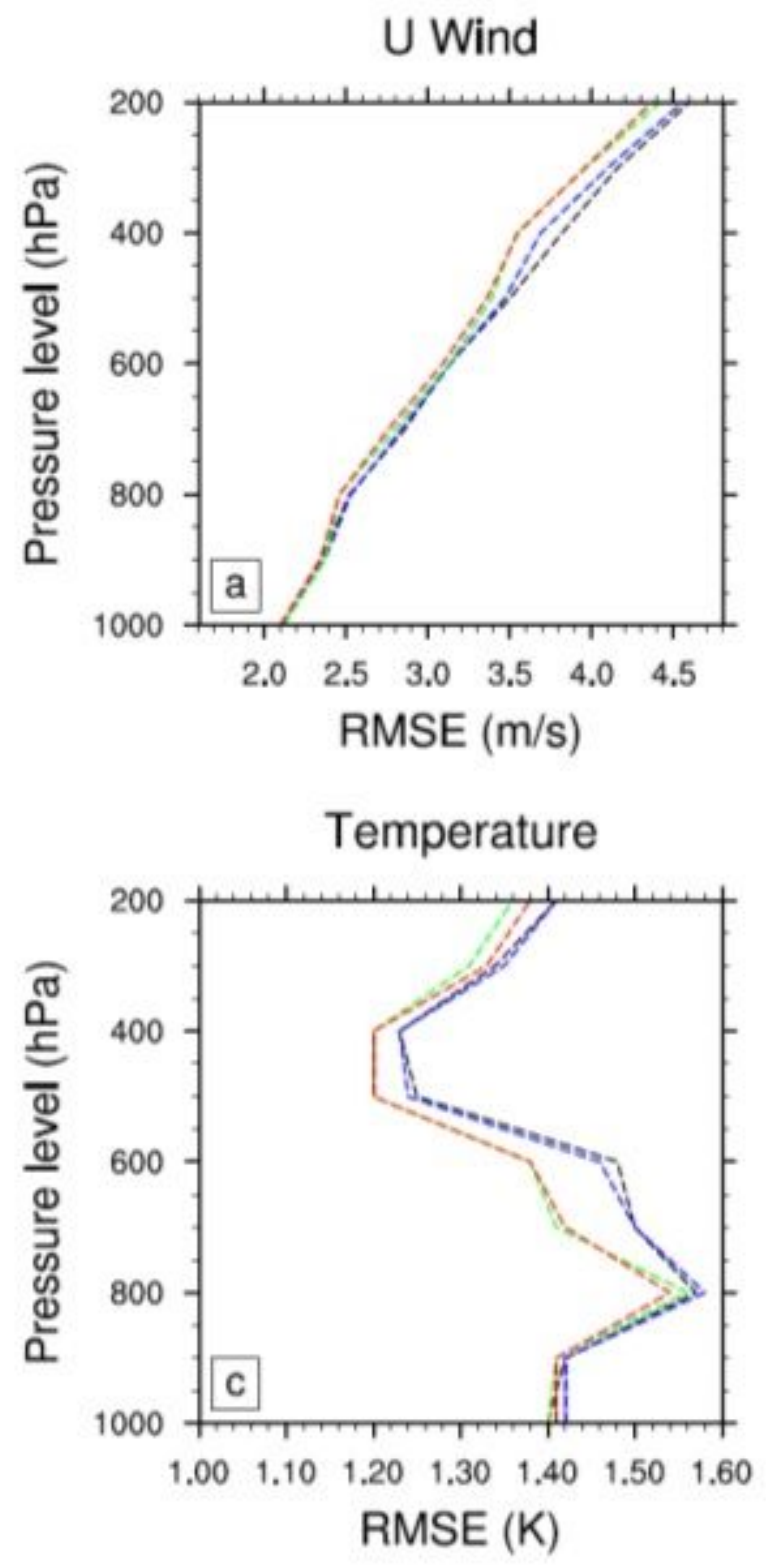
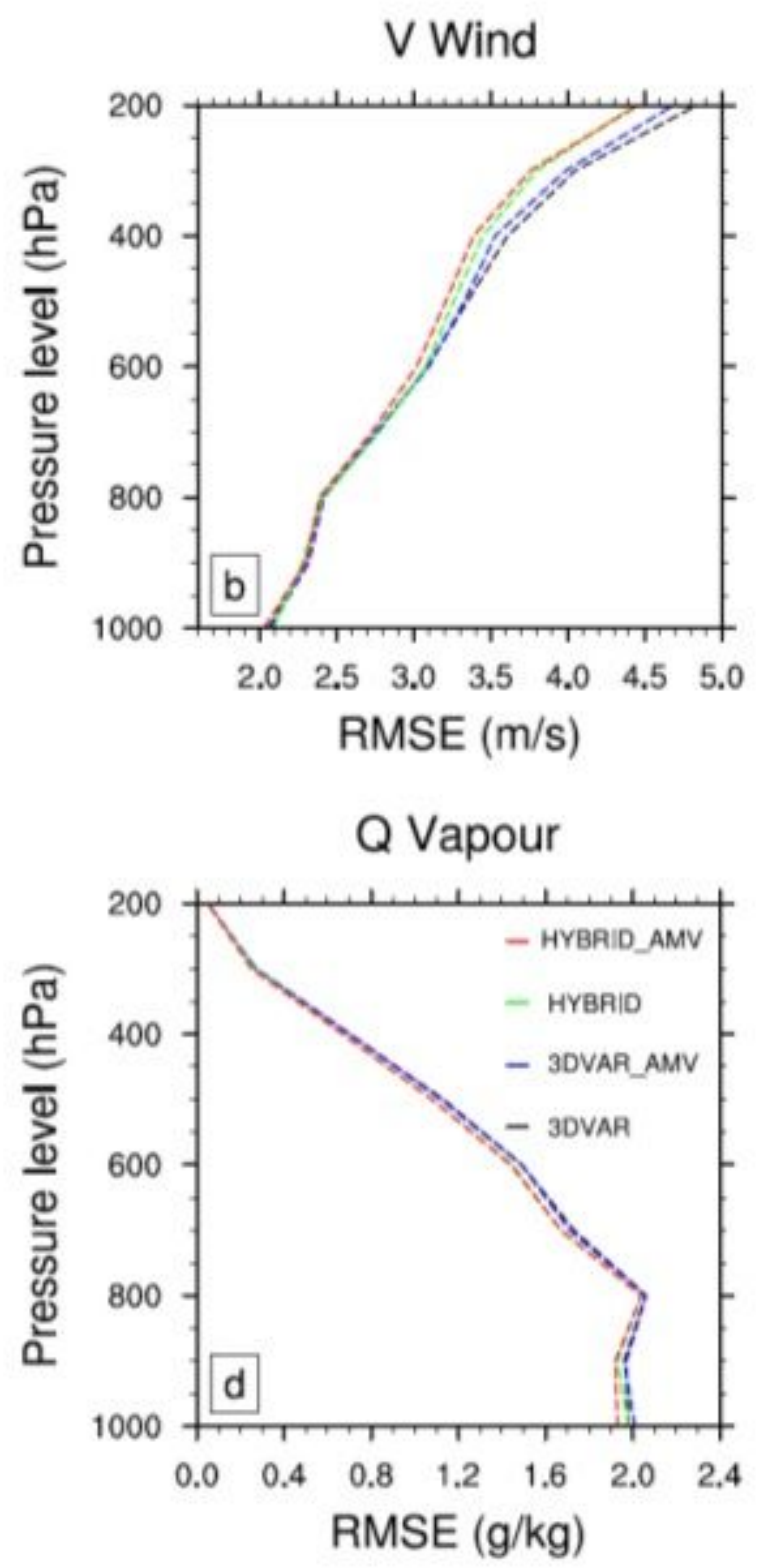

\section{Figure 4}

Vertical profiles of root mean square errors in $24 \mathrm{~h}$ forecasts from different experiments compared to radiosonde observations for different variables; 3DVAR (black line), 3DVAR_AMV (blue line), HYBRID (green line) and HYBRID_AMV (red line). 

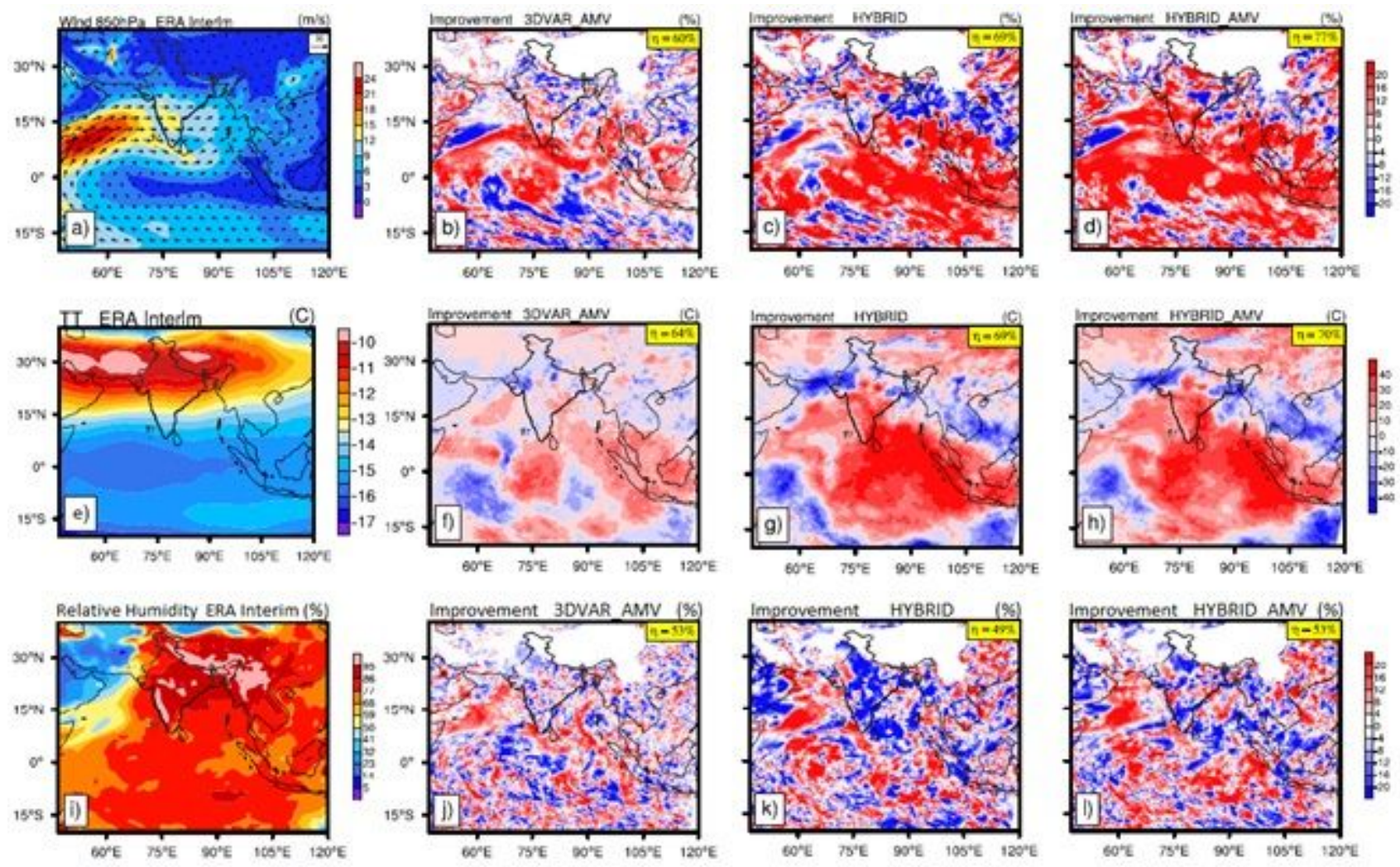

Figure 5

a) Monthly averaged wind $(\mathrm{m} / \mathrm{s})$ at $850 \mathrm{hPa}$ level, b) tropospheric temperature $(\mathrm{TT})\left(\mathrm{C}^{\wedge} \mathrm{o}\right)$ averaged over $200 \mathrm{hPa}$ to $700 \mathrm{hPa}$ level, c) relative humidity (\%) at $850 \mathrm{hPa}$ level from ERA interim and spatial distribution of improvement parameter $(\eta)$ in $24 \mathrm{~h}$ forecast of wind (b-d), TT (f-h) and relative humidity (jl) from 3DVAR_AMV, HYBRID and HYBRID_AMV system with respect to 3DVAR system.
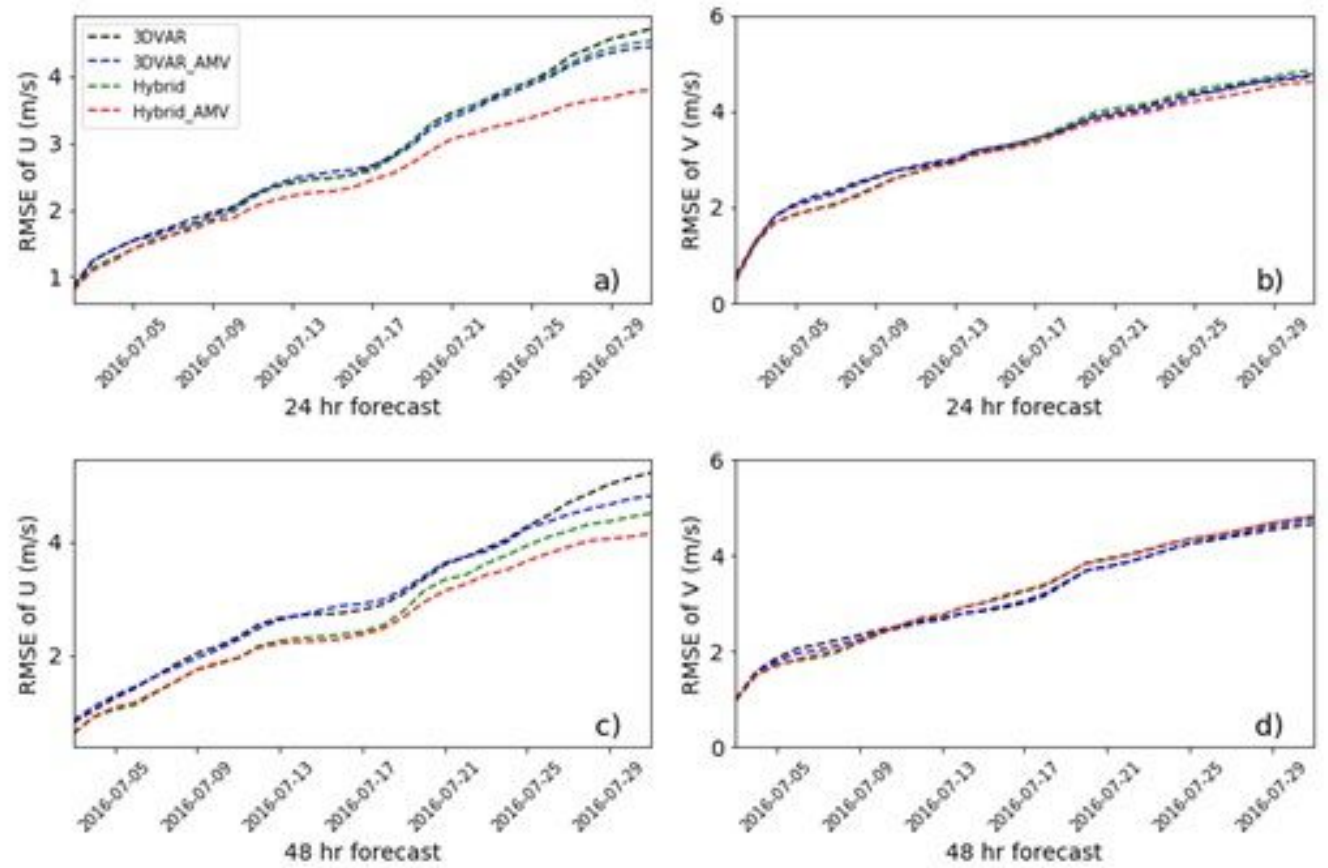
Figure 6

RMSE in $24 \mathrm{~h}(\mathrm{a}, \mathrm{b})$ forecast and $48 \mathrm{~h}(\mathrm{c}, \mathrm{d})$ forecast of $\mathrm{U}(\mathrm{m} / \mathrm{s})$ and $\mathrm{V}(\mathrm{m} / \mathrm{s})$ at $850 \mathrm{hPa}$ calculated over Arabian Sea from assimilation experiments with respect to ERA interim data for 3DVAR, 3DVAR_AMV, HYBRID, HYBRID_AMV
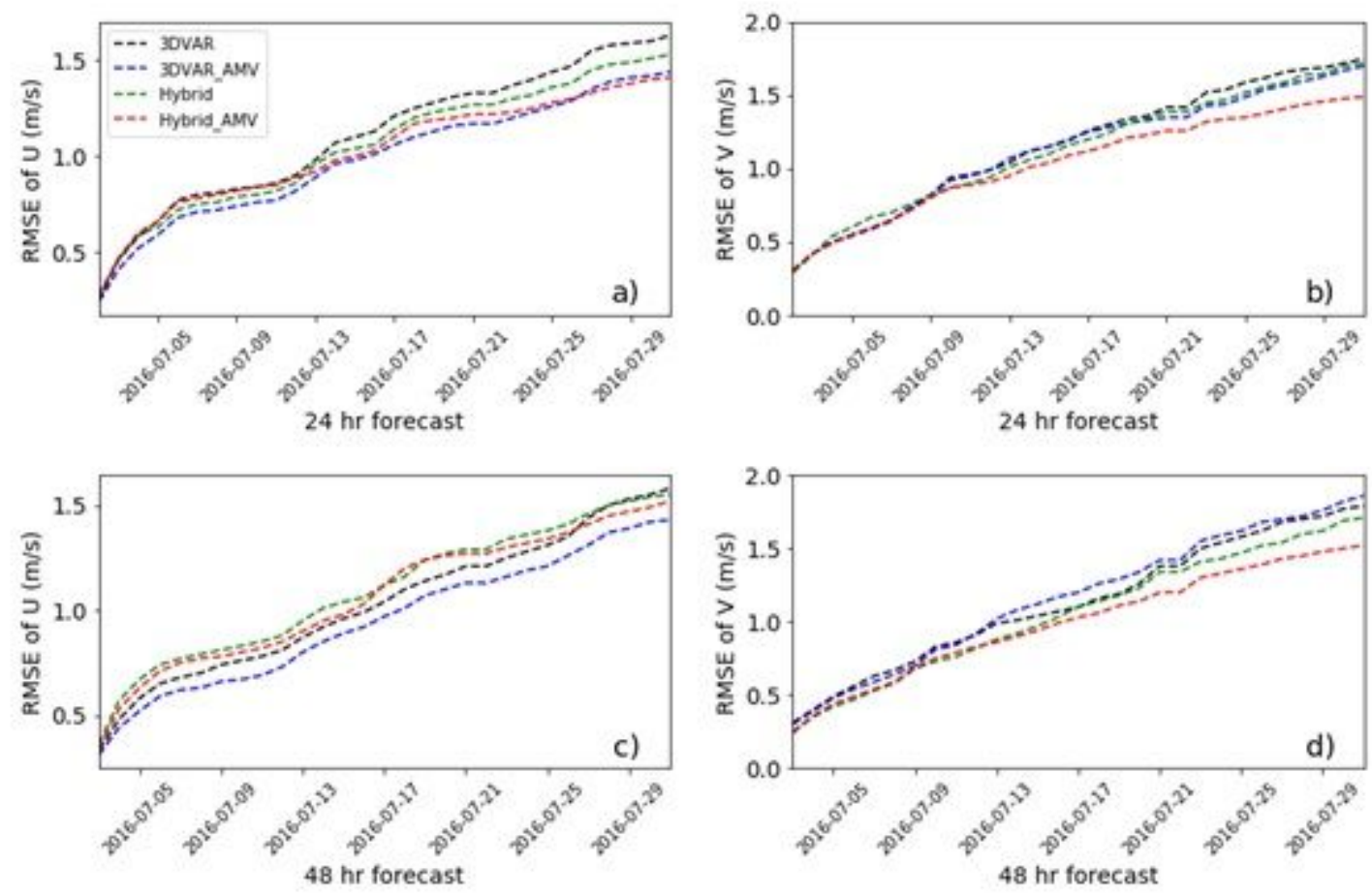

\section{Figure 7}

RMSE in $24 \mathrm{~h}$ forecast $(\mathrm{a}, \mathrm{b})$ and $48 \mathrm{~h}$ forecast $(\mathrm{c}, \mathrm{d})$ of $10 \mathrm{~m}-\mathrm{U}(\mathrm{m} / \mathrm{s})$ and $10 \mathrm{~m}-\mathrm{V}(\mathrm{m} / \mathrm{s})$ calculated over Arabian Sea from assimilation experiments with respect to ASCAT data for 3DVAR, 3DVAR_AMV, HYBRID, HYBRID_AMV 


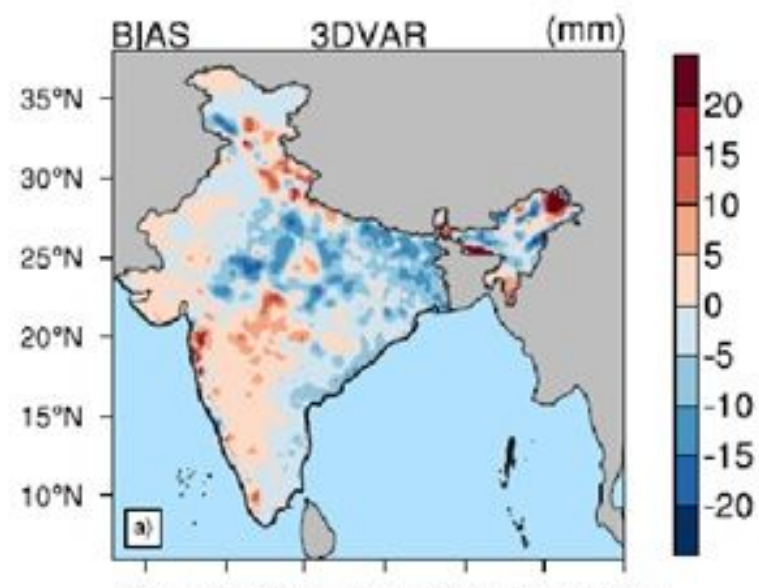

$70^{\circ} \mathrm{E} 75^{\circ} \mathrm{E} 80^{\circ} \mathrm{E} 85^{\circ} \mathrm{E} 90^{\circ} \mathrm{E} 95^{\circ} \mathrm{E} 100^{\circ} \mathrm{E}$

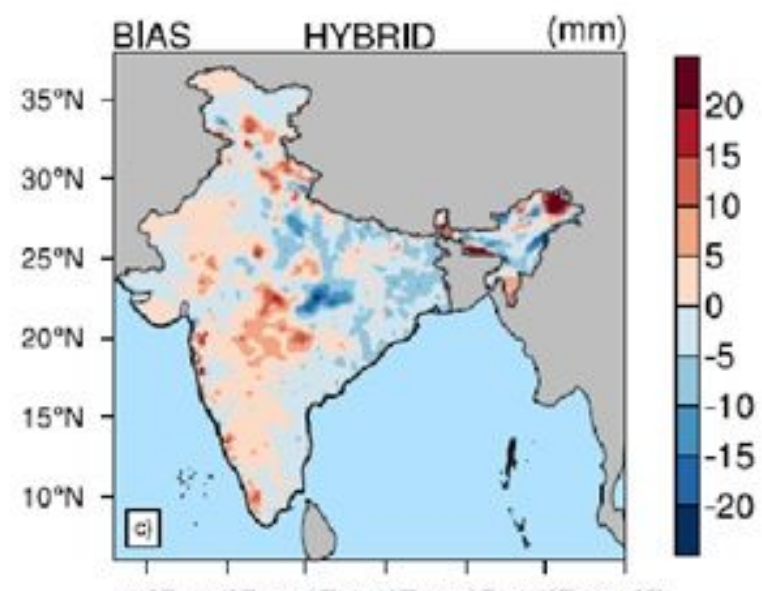

$70^{\circ} \mathrm{E} 75^{\circ} \mathrm{E} 80^{\circ} \mathrm{E} 85^{\circ} \mathrm{E} 90^{\circ} \mathrm{E} 95^{\circ} \mathrm{E} 100^{\circ} \mathrm{E}$
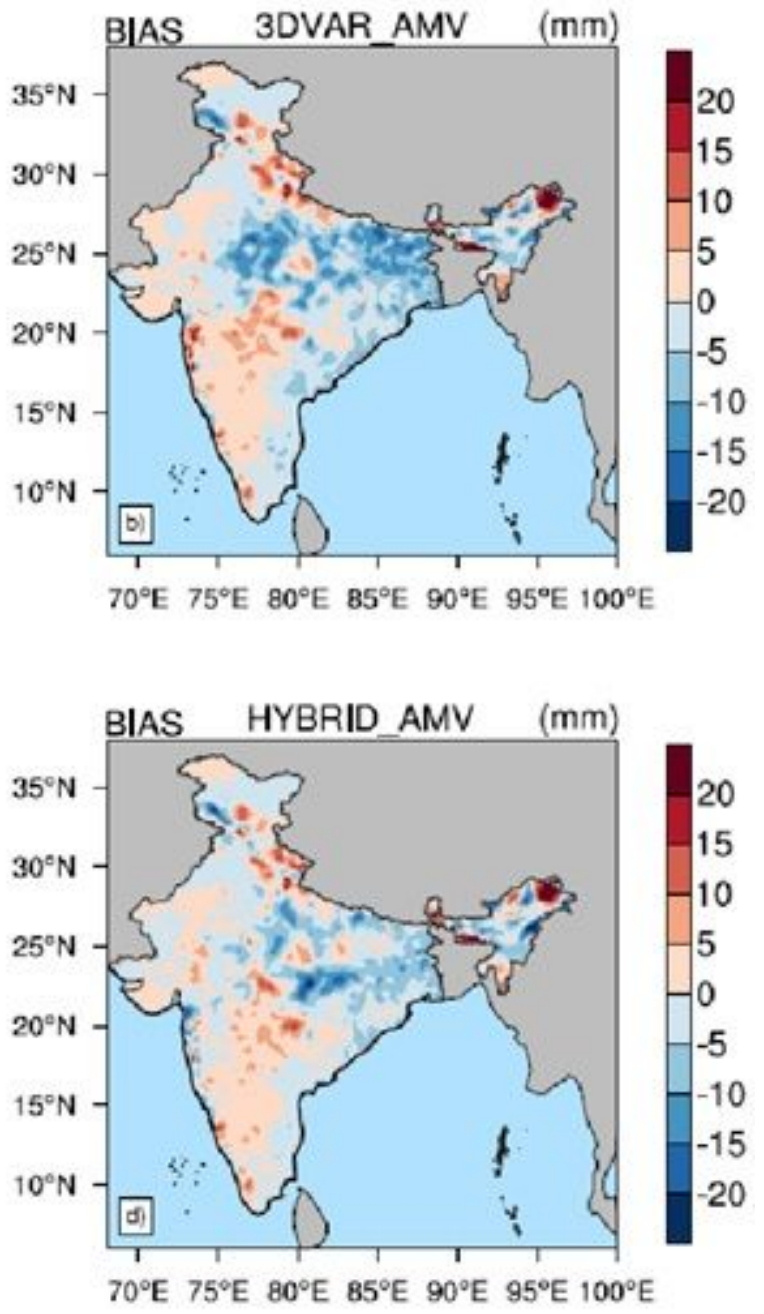

\section{Figure 8}

BIAS of monthly averaged (July) $24 \mathrm{~h}$ forecasted rainfall ( $\mathrm{mm} /$ day) with respect to IMD gridded rainfall for (a) 3DVAR (b) 3DVAR_AMV (c) HYBRID and (d) HYBRID_AMV 
(a)Equitable threat score

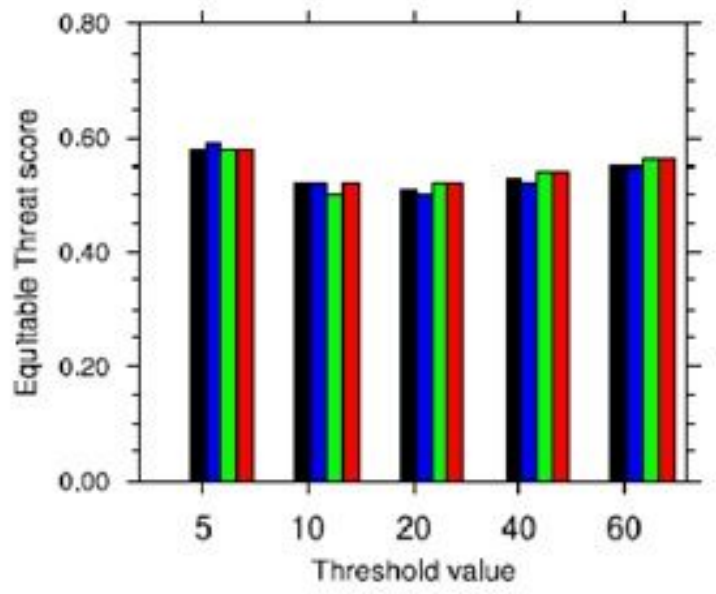

(c)Equitable threat score

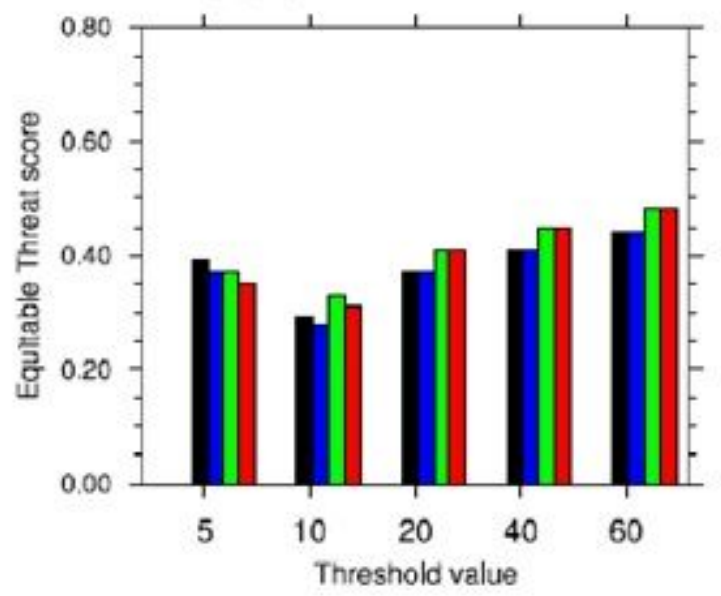

(b)Bias Score

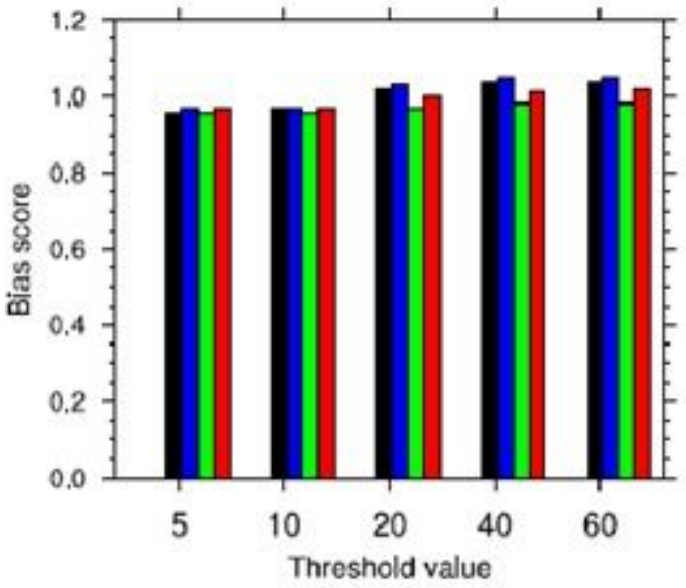

(d)Bias Score

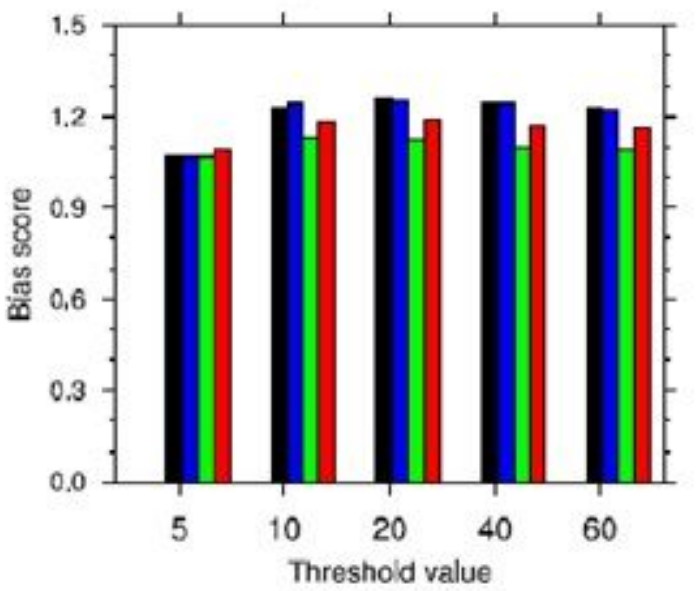

SDVAR

3DVAR_AMV $\square$ HYBRID

HYBRID_AMV

Figure 9

(a) ETS and (b) Bias scores valid from 2nd July 2016 to 16th July 2016 (first phase) and the (c) ETS and

(d) Bias scores valid from 17th July 2016 to 31st July 2016 (second phase) for different rainfall thresholds computed over the Indian land mass averaged over the 24 hour forecasts 
(a)Equitable threat score

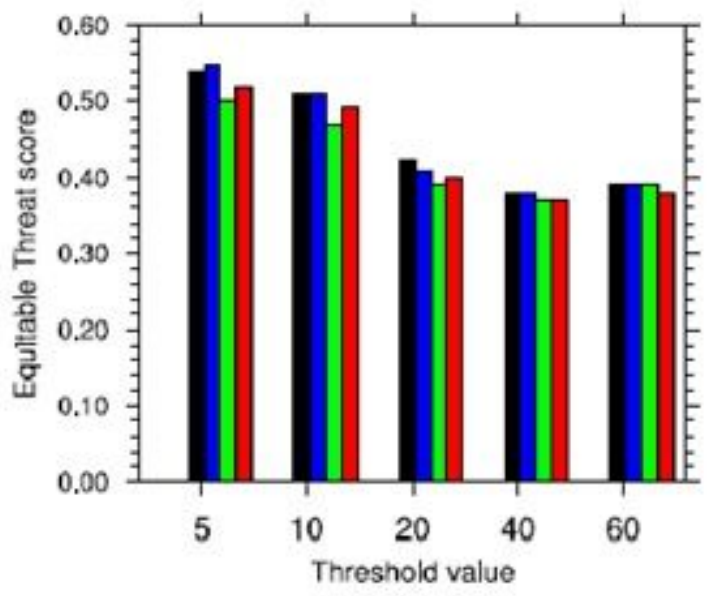

(c)Equitable threat score

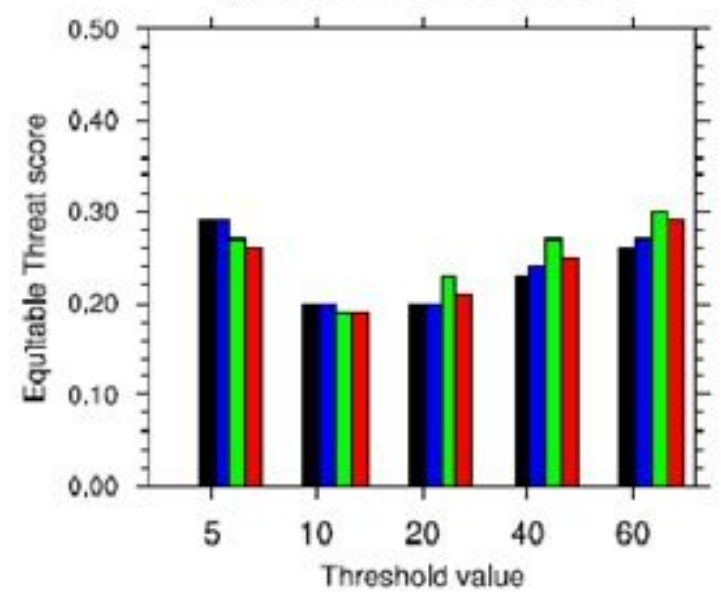

(b)Bias Score

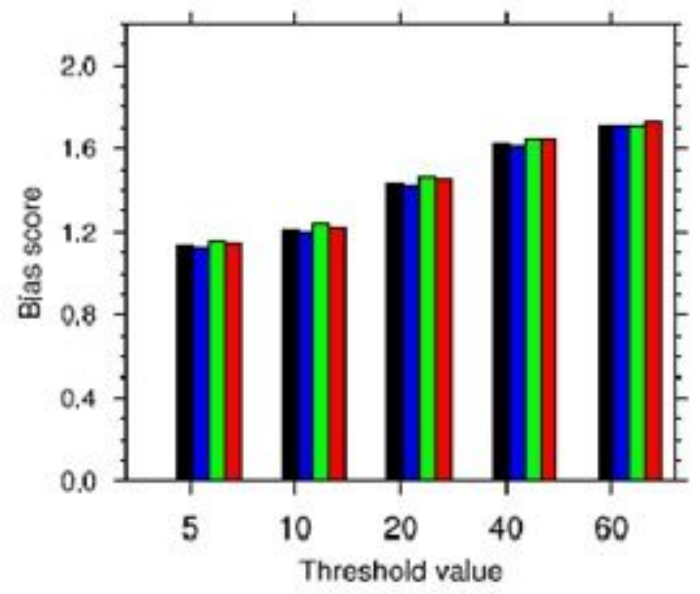

(d)Bias Score

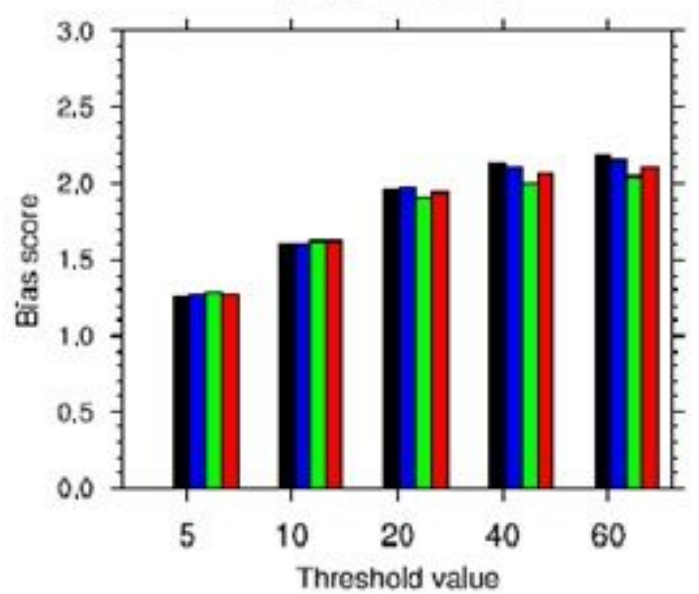

3DVAR

Figure 10

(a) ETS and (b) Bias scores valid from 2nd July 2016 to 16th July 2016 (first phase) and the (c) ETS and

(d) Bias scores valid from 17th July 2016 to 31st July 2016 (second phase) for different rainfall thresholds computed over the Indian land mass averaged over the 48 hour forecasts 